Disclosure of Interests: Alen Zabotti Speakers bureau: UCB, Novartis, Janssen, Paid instructor for: Amgen, Consultant of: Janssen, Orazio De Lucia Speakers bureau: Not relevant for this type of study, Consultant of: Not relevant for this type of study, Grant/research support from: Not relevant for this type of study, Garifallia Sakellariou Consultant of: AbbVie, Novartis, Alberto Batticciotto Speakers bureau: Not relevant for this type of study, Consultant of: Not relevant for this type of study, Grant/research support from: Not relevant for this type of study, Gilberto Cincinelli: None declared, Ivan Giovannini: None declared, Luca Idolazzi Speakers bureau: Eli Lilly, UCB, Celgene, MSD, Abbvie, Novartis, Paid instructor for: UCB, Gabriella Maioli Speakers bureau: Not relevant for this type of study, Consultant of: Not relevant for this type of study, Grant/research support from: Not relevant for this type of study, Ilaria Tinazzi Speakers bureau: Not relevant for this type of study, Consultant of: Not relevant for this type of study, Grant/research support from: Not relevant for this type of study, Daniel Aletaha Speakers bureau: not relevant for this type of study, Consultant of: not relevant for this type of study, Grant/research support from: not relevant for this type of study, Salvatore De Vita Consultant of: GSK, Roche, Grant/research support from: Not relevant for this type of study, Antonio Marchesoni Speakers bureau: not relevant for this type of study, Consultant of: not relevant for this type of study, Grant/research support from: not relevant for this type of study, Josef S. Smolen Speakers bureau: Not relevant for this type of study, Consultant of: Not relevant for this type of study, Grant/research support from: Not relevant for this type of study, Annamaria lagnocco Speakers bureau: not relevant for this type of study, Paid instructor for: not relevant for this type of study, Consultant of: not relevant for this type of study, Grant/research support from: not relevant for this type of study, Dennis McGonagle Speakers bureau: ABBVIE, CELGENE, PFIZER, MSD, NOVARTIS, JANSSEN, UCB, GILEAD, BMS, LILLY, Grant/research support from: ABBVIE, CELGENE, PFIZER, MSD, NOVARTIS, JANSSEN, UCB, GILEAD, BMS, LILLY, Roberto Caporali Speakers bureau: Abbvie, Amgen, BMS, Celltrion, Galapagos, Gilead, Lilly, Pfizer, Roche, UCB, Sanofi, Fresenius Kabi, Samsung bioepis, MSD, Consultant of: Galapagos, Gilead, Lilly, Janssen, MSD DOI: 10.1136/annrheumdis-2021-eular.1513

\section{POS0146 \\ PERIPHERAL NEUROPATHY IN PSORIASIS AND PSORIATIC ARTHRITIS: A SINGLE BLIND, CONTROLLED, ELECTROPHYSIOLOGICAL STUDY}

M. Izci', S. Kanyılmaz Turgut ${ }^{1}$, O. Akan ${ }^{2}$, I. Topal ${ }^{3}$, O. Kuru ${ }^{1} .{ }^{1}$ Prof Dr Cemil Tascioglu City Hospital, Physical Medicine and Rehabilitation Clinic, İstanbul, Turkey; ${ }^{2}$ Prof Dr Cemil Tascioglu City Hospital, Neurology Clinic, İstanbul, Turkey; ${ }^{3}$ Prof Dr Cemil Tascioglu City Hospital, Dermatology Clinic, İstanbul, Turkey

Background: It is well known that both psoriasis (PsO) and psoriatic arthritis (PsA) causes morbidity and disability in patients' lives. Additional pathologies such as peripheral neuropathy (PN) may interfere with disease specific symptoms and may increase the burden of disease. Neuropathic complaints of patients with PSO and PsA are observed during patients' follow-up $(1,2)$. However, the presence of PN in PsO and PsA is not well defined in clinical studies and clinicians might be neglecting this issue.

Objectives: Our aim was to investigate the presence of PN by electrophysiological methods and to examine its relationship with neuropathic pain and with treatments in patients with $\mathrm{PsO}$ and PsA.

Methods: 38 patients with PsA, 36 patients with $\mathrm{PsO}$ and 37 age\&sex-matched healthy volunteers were enrolled into this prospective, single-blind study. Disease activity was assessed with Psoriasis Area Severity Index (PASI) for patients with $\mathrm{PsO}$ and with Disease Activity in Psoriatic Arthritis (DAPSA) score for patients with PsA. Leeds Assessment of Neuropathic Symptoms and Signs (LANSS) score was used to evaluate neuropathic pain. All participants were electrophysiologically examined in Electromyography (EMG) Laboratory by an experienced neurologist blinded for study groups.

Results: There were no significant differences on patients age, sex and body mass index among 3 study groups ( $>0.05$ ). However, disease duration was significantly longer in PsO group compared to PsA group (median 19.1[1-43] years in $\mathrm{PsO}$ vs median $7.5[2-29]$ years in $\mathrm{PsA} ; \mathrm{p}<0.01$ ). $\mathrm{PN}$ was detected in 7 patients
(19.44\%) in the PsO group, 14 patients (34.21\%) in the PsA group, and in 1 volunteer $(2.7 \%)$ in the control group (PsO vs control: $p<0.05$; PsA vs control: $p<0.001$, PsO vs PsA: p>0.05) (Table 1). Among patients with PsA, 1 patient had ulnar neuropathy and 1 patient had both carpal tunnel syndrome (CTS) and sensory polyneuropathy. All other PNs detected electrophysiologically were CTS. Neuropathic pain was present in 11 patients $(30.56 \%), 20$ patients $(52.63 \%)$ and in 2 volunteers $(5.41 \%)$ in $\mathrm{PsO}, \mathrm{PsA}$ and control groups consecutively (PsO vs control: $p<0.05$; PsA vs control: $p<0.001, P s O$ vs PsA: $p>0.05)$. PN did not show any significant correlation with disease activity or treatments including biological agents.

Conclusion: To our knowledge, this is the first study to investigate simultaneously the presence of neuropathic pain and PN by electrophysiological methods in patients with $\mathrm{PsO}$ and PsA. We observed PN and neuropathic pain high in patients with PsO\&PsA and among them CTS appears as the most prominent neuropathy. Clinicians should keep this in mind during routine care of patients with $\mathrm{PsO}$ and PsA, which may improve patient-centred care. Large, prospective studies are needed to understand the characteristics of these neuropathies and its prognosis.

\section{REFERENCES:}

[1] Rifbjerg-Madsen S, Christensen AW, Christensen R, Hetland ML, Bliddal H, Kristensen LE, Danneskiold-Samsøe B, Amris K (2017) Pain and pain mechanisms in patients with inflammatory arthritis: a Danish nationwide cross-sectional DANBIO registry survey. PLoS One 12(7):e0180014.

[2] Ljosaa TM, Mork C, Stubhaug A, et al. Skin pain and skin discomfort is associated with quality of life in patients with psoriasis. J Eur Acad Dermatol Venereol. 2012;26:29-35.

Disclosure of Interests: None declared

DOI: 10.1136/annrheumdis-2021-eular.1258

\section{POS0147 ANALYSIS OF VENOUS THROMBOEMBOLIC RISK AMONG PSORIATIC ARTHRITIS PATIENTS}

T. Gazitt ${ }^{1}$, J. Pesachov ${ }^{2}$, I. Lavi ${ }^{3}$, M. Elias ${ }^{1}$, A. Haddad ${ }^{1}$, I. Feldhamer ${ }^{4}$, A. Cohen ${ }^{4}$, W. Saliba ${ }^{3}$, D. Zisman ${ }^{1,5} .{ }^{1}$ Carmel Hospital, Rheumatology, Haifa, Israel; ${ }^{2}$ Technion - Israel Institute of Technology, Ruth and Bruce Rappaport Faculty of Medicine, Haifa, Israel; ${ }^{3}$ Carmel Hospital, Community Medicine and Epidemiology, Haifa, Israel; ${ }^{4}$ Clalit Health Organization, Chief Physician's Office, Central Headquarters, Tel Aviv, Israel; ${ }^{2}$ Technion - Israel Institute of Technology, Ruth and Bruce Rappaport Faculty of Medicine, Haifa, Israel

Background: Psoriatic arthritis (PsA) is a chronic, immune-mediated, systemic inflammatory arthritis associated with comorbidities including metabolic syndrome, cardiovascular risk factors and cardiovascular disease (CVD).

Objectives: To evaluate the prevalence of venous thromboembolism (VTE) in a PsA patient cohort using a large health care provider database.

Methods: A large health care provider database serving 4.7 million healthcare subscribers was interrogated for an adult patient cohort who were newly diagnosed with PsA between January 2005 (start date) and 31 December 2018 with date of diagnosis considered the index date. A risk set was employed to randomly select 4 controls without PsA as a comparator group to the PsA cohort matched by age, sex, ethnic group, and index date. Both groups were followed from the index date until the first occurrence of VTE event, death, or end of follow-up 31 December 2019, whichever came first. Marginal model with robust covariant estimate counting for the matching was used to estimate the crude and adjusted hazard ratio (HR) for the association between PsA and VTE. Within the group of PSA patients, Cox proportional hazard regression models was used to calculate the risk of having VTE given demographic variables, SES, smoking, selected comorbidities, and conventional vs biologic disease modifying anti-rheumatic drugs (c/bDMARD). Continuous variables were summarized with mean \pm standard deviation, and categorical variables were presented as numbers and proportions. All tests were 2-sided; $p$ values of $<=0.05$ were considered statistically significant. All data were analyzed using SPSS, 24 (IBM SPSS Statistics for Windows, version 24.0, 2016, Armonk, NY) and SAS, 9.4 (SAS institute Inc, Cary, NC).

Table 1. Results of peripheral neuropathy and neuropathic pain in control group and patients with PsO and PsA

\begin{tabular}{|c|c|c|c|c|c|c|}
\hline & Control Group $(n=37)$ & PsO Group $(n=36)$ & PsA Group $(n=38)$ & $p^{\wedge}$ & $\mathrm{p}^{+}$ & $p^{\&}$ \\
\hline CTS & $1(\% 2.70)$ & 7 (\%19.44) & $13^{*}(\% 34.21)$ & $0.028^{\mathrm{a}}$ & $<0.001^{\mathrm{a}}$ & $0.153^{a}$ \\
\hline Ulnar Neuropathy & 0 & 0 & $1(\% 2.63)$ & & & \\
\hline Polyneuropathy & 0 & 0 & $1^{\star}(\% 2.63)$ & & & \\
\hline Total PN & $1(\% 2.70)$ & 7 (\%19.44) & $\begin{array}{l}14 \\
(\% 36.64)\end{array}$ & $0.028^{a}$ & $<0.001^{a}$ & $0.097^{\mathrm{a}}$ \\
\hline $\begin{array}{l}\text { LANSS Score } \\
\text { According to LANSS }\end{array}$ & $5(0: 13)$ & $6.50(0: 16)$ & $13(3: 19)$ & $0.170^{\mathrm{b}}$ & $<0.001^{\mathrm{b}}$ & $0.004^{b}$ \\
\hline likely neuropathic pain & $2(\% 5.41)$ & $11(\% 30.56)$ & $20(\% 52.63)$ & $0.005^{\mathrm{a}}$ & $<0.001^{\mathrm{a}}$ & $0.054^{\mathrm{a}}$ \\
\hline
\end{tabular}

*: Both polyneuropathy and CTS were detected in one patient in the PsA group; Data are given as $n$ (\%) and median (minimum: maximum); a: Chi-Square Test, b: Kruskal Wallis Test; $\mathrm{p}^{\wedge}$ value: control vs $\mathrm{PsO}, \mathrm{p}^{+}$value: control vs PsA, $\mathrm{p}^{\&}$ value: $\mathrm{PsO}$ vs PsA 